\title{
The Dependence of Value on Humanity
}

\section{Citation}

Korsgaard, Christine M. 2003. "The Dependence of Value on Humanity." In The Practice of Value, by Joseph Raz, 63-85. Oxford: Oxford University Press.

\section{Published Version}

doi:10.1093/acprof:oso/9780199278466.003.0004

\section{Permanent link}

http://nrs.harvard.edu/urn-3:HUL.InstRepos:29429747

\section{Terms of Use}

This article was downloaded from Harvard University's DASH repository, and is made available under the terms and conditions applicable to Other Posted Material, as set forth at http:// nrs.harvard.edu/urn-3:HUL.InstRepos:dash.current.terms-of-use\#LAA

\section{Share Your Story}

The Harvard community has made this article openly available.

Please share how this access benefits you. Submit a story.

Accessibility 
The Dependence of Value on Humanity

Commentary on Joseph Raz, The Practice of Value

By Christine M. Korsgaard

I begin with one of Raz's own examples. We admire one building for its flights of fancy and inventiveness; we admire another for "spare minimalism and rigorous adherence to a simple classical language."(REF) The values we find embodied in the two buildings seem opposed, almost contradictory. Do we contradict ourselves? Not necessarily, according to Raz, for the buildings represent two different architectural genres, the romantic and the classical: each of the buildings may be a good building of its kind.

From this apparently innocuous conclusion we can work backwards to Raz's more controversial ideas. The example helps to show that what may look at first glance like an instance of social or cultural relativism is actually just a case of social or cultural dependence. The values of romantic architecture depend upon a practice, namely the practice of romantic architecture. This practice arose within a particular culture, at some particular time and place. The people who practice romantic architecture are, in some sense, trying to realize the values of romantic architecture. The qualifier "in some sense" is needed here, as Raz reminded us in his first lecture, for the practitioners might not have been able to describe themselves in just that way. We can easily see this by switching to the other side of the example. The first practitioners of classical architecture could hardly have described themselves as trying to realize the values of classical architecture, since of course those values had not yet become classical. But the earliest classical architects were presumably doing something we could count as trying to realize the values of classical architecture: say, they were aiming at a certain symmetry or serenity or solidity that people later came to identify as classical.

But now, we might ask, doesn't that very description undercut the thesis that values are socially dependent? Symmetry and serenity and solidity are not, or anyway not obviously, socially dependent attributes, and if these attributes are the values in question, then the values are not socially dependent either. Whatever we decide about that question, Raz will reply, it is not an objection, because a list of such attributes is only a kind of shorthand way of referring to the relevant values anyway. The values of classical architecture are not 
symmetry and serenity and solidity, but rather a certain characteristic way of combining these attributes, and of realizing them in certain building materials, and in the contours and decor of rooms and entryways. The values of classical architecture are, in short, values specific to classical architecture, so specific that they can only be gestured at in general terms.

And that is the part of the point. The values of classical architecture are in fact so specific to classical architecture that they can only be realized in classical architecture. Therefore until classical architecture existed, neither did its values. That is why the values depend on the practice, and only came into being with it. But once they exist, they are not relative values. I quote Raz: "Once a value comes into being it bears on everything, without restriction. But its existence has social preconditions.” (REF)

As Bernard Williams also points out, that "bears on everything, without restriction" is slightly obscure. Once the values of classical architecture exist, they bear on everything that wants to be classical architecture, to be sure. And that is not a normatively toothless point, for in light of it it will be true that some buildings are badly done, whether anyone thinks so or not. The critic who does think so will be seeing something that is the case, not just exercising his taste. Or rather, to put the point in a better way, he is exercising his taste, but his taste is a form of intelligent perception, not just a source of raw likes and dislikes. But on what else do these values bear? They do not bear on seashells or toaster ovens or rabbits - we do not judge these to be good or bad instances of classical architecture. Do they bear on other buildings? Once the values of classical architecture exist, it does become intelligible to ask whether buildings built later in the Western European tradition realize these values, but as Raz's own example suggests, we do not necessarily think the worse of them if they do not. Does it also become intelligible to ask whether buildings built later in Africa, or if it so happens on Mars, realize these values? I do not find this obvious myself. And if not, why isn't this a kind of cultural relativism after all? Cultural relativism is not supposed to be the same thing as a raw individual subjectivism of taste, and that, so far, seems to be the only position that has been rejected. 
But actually I do not want to pursue this sort of argument, which I can leave to Bernard Williams. ${ }^{1}$ My interest is not in pressing Raz in the direction of cultural or social relativism, but rather in the opposite direction: towards what we might call the natural dependence of value, specifically its dependence on an old-fashioned item called human nature.

But let me first say a word more about Raz's basic idea: a value comes into being at a particular time, but once it comes into existence it bears on everything. It might seem paradoxical to say that values are the contingent products of historical events, and yet that they are eternal, which is what Raz is saying. But actually the structure here is one that we should recognize. For I think that this is true - and that most of you think it is true - of people, normatively considered, that is, considered as sources of reasons and bearers of rights.

Let me show you what I mean by this. Let us suppose, just for the sake of the argument, that people come into existence at birth. Of course there are controversies about this, but leave those aside for now. Compare two cases: A first woman takes drugs knowing that she is pregnant, damages the fetus in some horrible way, and then decides to abort. A second woman takes drugs knowing that she is pregnant, damages the fetus in some horrible way, and brings it to term and gives birth. The first woman, in my view, may have wronged herself, may in certain circumstances have wronged the potential father, and has certainly shown a pathetic lack of reverence for life. But she has not wronged the person whom that fetus might someday have been, because there is no such person. That person, on the hypothesis that people begin to exist at birth, never came into existence. But the second woman has wronged the person whom her fetus becomes, and that person has claims against her. And this is because a person, once he does exist, is a source of reasons and rights that bear on everything, without restriction. His claims extend backward into the past as well as forward into the future.

The point also applies to a current debate about the preservation of the environment. Some philosophers argue that the people who will exist in the future will not have claims against us for leaving the world, as we will, overheated, polluted, biologically

\footnotetext{
1 See Bernard Williams, Ethics and the Limits of Philosophy (Cambridge, MA.: Harvard University Press: 1985) especially chapter nine, for an argument that it may simply be pointless to judge one culture in terms of another culture's values.
} 
impoverished, and extensively paved. The people who will exist in the future will not have claims against us because they will be different individual people than the ones who would have existed if we had lived differently. Therefore we could not be wronging them by living as we do. I think this claim is false. Once those individual people exist, whoever they are, they will have claims against us for mucking up the world. People come into existence at a particular time, and it is utterly contingent which people happen to exist. ${ }^{2}$ But once they exist, people are the source of objective normative claims that extend backward into the past and forward into the future, and in Raz's words, bear on everything, without restriction.

Joseph Raz thinks that values are like that. They come into being at a particular time, and it is deeply contingent which ones exist. But once they exist they exert objective normative claims that bear on everything, without restriction. This comparison between people and values is not a merely fanciful one, since, as I have tried to suggest, the two cases do have something in common: I think people are, and Raz thinks values are, the sources of normative claims.

In making these remarks I have borrowed Raz's language of "the existence of values," which Bernard Williams in his comments objects to. So I would like to pause here and add a few words about that. One of the difficulties of philosophizing about value or perhaps especially about "values" is that the term gets applied to a number of different kinds of items. First there are the valuable objects themselves: for instance the operas, flowers, friendships, sunsets, and liberal governments that are serving as our examples in this discussion. Then there are the properties in virtue of which we deem these things valuable: in architecture, inventiveness and symmetry; in friendship, intimacy, loyalty, company, and sharing; in flowers, appealing colors and shapes and scents. Third, there is the valuableness, or normative claim, that we attribute to the objects in virtue of those properties - the building is valuable in virtue of its inventiveness, the flower in virtue of its scent, say. Very abstract value terms, like beauty, may not refer to any of those things, but rather to

2 "Which people" carries the odd suggestion that there is a set of potential people, some of whom come into existence: the lucky ones, so to speak. That is a thought more at home in the view I am objecting to, which identifies particular people in terms of DNA combinations. My point here is just that the existence of particular people is contingent in the same sense that the existence of particular 
complexes of them: we might say that a beautiful thing is an object we value in virtue of its appearance or perceptible nature, or something like that.

I think that Raz, in speaking of value, allows the term to slip around a bit among these different items, in particular between the properties in virtue of which we deem an object valuable and the value we assign to the object in virtue of those properties. The term “excellence of," a favorite of Raz's, encourages us to slip in exactly that way. And I do not think the slip is innocuous, because I think it might be what tempts Raz to think that an object may be good in virtue of being good of its kind - a point to which I will recur shortly.

But to go back to the question of "existence": there is obviously no difficulty about the existence of the object, and I think that any difficulty about the existence of the properties is inherited from an apparent difficulty about the existence of the third thing - the valuableness or normative claim we assign to the object in virtue of its having the properties. My own view is that talk of the existence of values at this level is just misleading shorthand for something else, namely valuing, which is a thing that we do. To say that something is valuable in this sense is to say that people appropriately value it. Some people will suppose that the only way to earn the right to that "appropriately" is to posit "real" values "out there in the world" that valuing, so to speak, tracks. But actually that does not follow. There is no activity - not even desiring - that you can do any way that you like. Valuing has its rules: it is something you do in virtue of a thing's properties, it is to that extent communicable to others, it trumps mere local preference, and so on. We may grant that this just moves a whole set of problems over to the activity of valuing and what its determinate limitations and demands might be. But at least it moves it over to something that unquestionably does exist, namely, the human activty of valuing -- or as I have called it elsewhere, conferring values. ${ }^{3}$

Let us return to the issue of pluralism. Raz notes that someone might object that he is overemphasizing the analogy between aesthetic values and values generally: aesthetic values may be relativized to genre without losing their objectivity, but this does not show that values in general may be relativized without loss of objectivity. In response to this

values, according to Raz, is contingent. Raz sometimes does seem to think that there is a set of potential values, some of which come into existence.

3 "Kant's Formula of Humanity" in Creating the Kingdom of Ends (New York: Cambridge University Press, 1996). 
worry Raz points out that something like genre-based thinking applies across the board. Just as a building is good or bad as a piece of classical architecture, so a lecture is good or bad as a lecture, a vacation is good or bad as a vacation, and so on. There is, Raz tells us, a twostage process embedded in evaluation: we judge a thing to be good because it is good of its kind. I quote Raz: 'It is odd to say 'The lecture was good because it was a good lecture.' But that is how it is." (REF)

One obvious problem with this is that there are standards of excellence for very bad things: a good assassin is cool, methodical, careful, and ruthless, but we are not going to say "the assassin is good because he is a good assassin." Nor is it adequate merely to say that although he may be a good assassin we have other reasons to object to him. As Kant says, "the coolness of a scoundrel makes him not only far more dangerous but also immediately more abominable in our eyes than we would have taken him to be without it." ${ }^{4}$ So there is the problem of the bad genre.

But there is also an issue raised by the embeddedness of the genre in another wider genre, if we take the notion this generally. To switch terms, a genre is a kind of species of a wider genus, and that may in turn be a species of a wider genus still. Aristotle thought it was the nature of the world to be divided up in this way, or perhaps we may think it is the nature of human beings to conceptualize the world in this way. This, as I am about to argue, implies that the relation between pluralism and genre-based evaluation is not as straightforward as Raz suggests.

We need not judge the romantic building to be better or worse than the classical building, or to be bad because it lacks the properties that make the classical building good. We can make room for value pluralism, because we can say that each building is good of its kind, and leave it at that. But we need not admit value pluralism merely because we have made room for it. And we may not want to admit it in all cases. Someone might think that romantic architecture is better than classical architecture, just like that. I do not mean just that he likes it better, but that he thinks it is better. Is that incoherent? Given the genus/species structure of the world, it should not be incoherent on Raz's account, for there

4 Immanuel Kant, Groundwork of the Metaphysics of Morals, translated by Mary Gregor. (Cambridge: Cambridge University Press, 1997), p. 8; in the standard Academy edition page numbers found in the margins of most translations, p. 394. 
is a way to make the judgment: we just back up to the wider genre or genus, and judge on the basis of values definitive of it. What is the wider genre or genus in this case? Western architecture? Decorative architecture? How about "architecture"?

Are the values of architecture, just as such, socially dependent? No matter what society they live in, human beings must have some sort of architectural practice. Given that buildings have a general function in human life, they must meet certain universal normative standards, standards that enable them to serve those functions, and the result will be universal architectural values. And those values might conceivably determine that one genre is better than another.

Now we may imagine the value pluralist countering this point in the following way. Any universal architectural norms that derived from the function of buildings in human life would be instrumental norms. So the universal values of architecture, just as such, are only instrumental values: the rooms must be tall enough for people to stand up in, for instance. Now Raz asserted in the opening lines of his first lecture that instrumental values are not socially dependent, but are partly constituted by the facts. Raz's interest, in any case, is in intrinsic values. And if the argument I have just put in the pluralist's mouth were correct, then once we started judging buildings for their intrinsic values, we would have to appeal to the standards of some more specific architectural genre. All of the intrinsic value judgments we could make about architecture would still be socially dependent.

But I see no reason to believe that the values inherent in the practice of architecture just as such are merely instrumental. Or, to put the point in a better way, I see no reason to believe that the intrinsic/instrumental distinction is as hard and fast as all that. ${ }^{5}$ Whatever

5 That the intrinsic/instrumental distinction, using Raz's terminology for the moment, is not that hard and fast is one of the points defended in my "Two Distinctions in Goodness." (Creating the Kingdom of Ends, cited above.) Another is that we should not use the term "intrinsically valuable" to refer to things which are valued for their own sakes, since that is a different idea than the idea of something's having its value within it. That point is also relevant here. The sort of value Raz ascribes to opera is intrinsic in a third sense: the standards the good opera meets spring from its intrinsic nature as opera. They are what I call "internal standards"; and as I have argued elsewhere that this is an important idea. ("Self-Constitution in the Ethics of Plato and Kant, The Journal of Ethics 3: 1-29, 1999.) But as I will argue below, it does not automatically follow from the fact that something meets its internal standards that human beings have any reason to value it. 
values are grounded in the genre of architecture just as such spring from the fact that buildings must be suitable for human use. And "suitable" here can mean more than just that it is causally possible for human beings to use them. A sufficiently low ceiling might make a building literally impossible for human beings to use. But a slightly less low ceiling might be oppressive, or visually distracting, and that might be a fact that depends on our nature, rather than on cultural or social practice. I am not saying it is; the question whether a certain reaction depends on nature or culture is an empirical one, and the answer can be surprising. ${ }^{6}$ My point is just that the genre architecture as such - or, more precisely, the genre "building suitable for human use," might be the source of certain architectural values, values that could not without artificiality be categorized as instrumental. And these values would not be socially dependent. They would be dependent on human nature.

One might suppose that this sort of consideration does not apply to some of Raz's other examples - opera, for instance. Opera does not play a functional role in human life, the way buildings do. But this, to my mind, would be the same mistake again, of exaggerating how hard and fast the instrumental/intrinsic distinction is. Opera may not serve any purpose external to itself, but forms of music and story-telling seem to be common to most human societies, and activities that combine them are found in many. Opera is a genre of something more fundamental and broader that our nature calls for. It is hard to give that something a name without seeming to trivialize it - as "musical entertainment" does, for instance - but all the same there is something there.

In fact I believe there is something behind even these more fundamental and broader values; that is, something most fundamental of all. This most fundamental thing is deeply embedded in human nature, so deeply that it is difficult even to talk about, and it stands behind the whole range of our values. The Greeks called it a logos, Kant called it a ground, we might also call it a story, in the widest sense, as when philosophers say to each other "you have to have some story to tell about that." What is it? One thing does not merely follow another: it justifies it, explains it, rewards it, punishes it, it is its climax, its culmination, its fruition, or its doom. The relation between the two events or objects gives

\footnotetext{
6 The judgment that one person looks like another or that one word sounds like another feels primitive, immediate, and undeniable when you make it, as if it were just a straight sensory judgment. Yet that these judgments admit of cultural variation.
} 
both of them meaning and intelligibility; the direction of the relation gives a narrative structure to what happens, hence "story", we tell ourselves a story. This thing is equally behind our endless delight in narratives and our thirst for scientific explanation. It is a primitive form of value, inhabiting all others, a kind of general structure of value. Whatever else it does, a good opera, a good scientific explanation, a good philosophical account, or a good passage from one room to another in a house must tell us a story. Some people think that that basic structure is given to us by the world, but as a Kantian I think that the demand for it lies in us.

But leave that aside, and come back to our more down-to-earth question about pluralism. Could the architectural values grounded in human nature, the values of architecture as such, determine a single absolutely best or right form of, say, dwelling? I do not suppose that any of us will find this particular possibility tempting. This is in part because among the things that human beings in fact appreciate in architecture is variety. And it is in part because human nature is essentially exploratory, and the generation of multiple possibilities is part of what our nature determines. ${ }^{7}$ But nothing in what Raz has said here rules out the theoretical possibility that our nature might determine a best or right form of house, and so no decisive case has been made for value pluralism. And this is just as well. For we might then hope that the values grounded in human nature $d o$ in the end determine a single absolutely best or right form of political constitution. Perhaps we can still say that it is best or right for people to live in the Kingdom of Ends. And if we can see modern constitutional forms, with their increased emphasis on equality, as moving towards that Kingdom, perhaps a little modern moral bubris will be justified after all. ${ }^{8}$

To prevent confusion about the point I've just made, I should say that the optimism I mean to express is about the chances of grounding a conception of the right in human nature that would support some particular political forms over others. Although I've challenged Raz's argument for pluralism, I don't in general find pluralism about the good

\footnotetext{
7 I do not know whether I have just mentioned two facts or only one.

8 See Raz's remarks about how pluralism underlies Berlin and Walzer's rejection of "the hubris of moderns who believe that our ways are superior to those of all other human civilizations" (REF). Raz admits that certain moral values are not socially dependent, and of course he can make an
} 
implausible. On the contrary, I think that one of the most important attributes of humanity is our nearly bottomless capacity for finding sources of delight and interest in nearly anything, and so for conferring value on almost anything. This very fact about human nature is part of what makes it so essential that our relations to one another - both moral and political should not be mediated by our values. ${ }^{9}$ It is not because of our shared values that we should accord consideration to one another but because of our shared capacity for conferring value. In other words that fact about human nature is part of what makes liberal democratic forms of the state the right ones.

Raz associates his view about the social dependence of values with a thesis that has implications for the metaphysics of intrinsically valuable objects. He says:

The very idea of opera, friendship, or the state is a normative idea in that we understand the concept of an opera or friendship or of the state in part by understanding what a good opera is like, or a good, or successful friendship, or a good state. (REF)

The metaphysical implication is that opera, friendship, and the state are essentially normative entities, entities whose essence is constituted by the normative standards that govern them.

This is not to say that they have to meet those standards in order to be those kinds of entities, but rather that their identity is given by the fact that the standards apply to them. Actually, even "apply to them" may be too strict in some of the aesthetic cases. Raz mentions that we live in a time of aesthetic freedom and fluidity, in which the boundaries between genres are easily crossed, and violated in other ways. In such a situation, to say that something is a member of a certain genre may mean not that it meets the standards of that genre and not even that it tries to, but only that it is possible to talk about whatever it does do in relation to those standards. It may be that what it does is play with the standards of a

argument for the superiority of certain political forms on the basis of those. But, as I argue below, he appears to think that that is just a separate issue, and I think that misses something.

9 See my "The Reasons We Can Share" in Creating the Kingdom of Ends (New York: Cambridge University Press, 1996): pp. 275-310, especially the discussion on pp. 289-291. 
genre or comment on them or flout them deliberately. So we might count something as a novel precisely because in some identifiable way it keeps insisting that it is not a novel. It is a familiar point that many modern art forms are self-conscious and play with their own identities in this way. So we might say that things like opera, friendship, and the state are things that by their very nature want to be good opera, good friendship, or good political forms.

In a footnote (note 17), Raz notes that Hans Kelsen and John Finnis thought of "law" and "the state" as being normative in this way. But we can go back a little further than that, for the idea that the state is in this way an essentially normative entity, only to be understood in terms of its ideal form, is the idea of Plato's Republic. In fact, arguably, it is The Idea, period. That is roughly what Plato thought.

I will come back to that point. But first, notice that Raz's point about normative identity does not apply only to intrinsically valuable cultural objects. It applies, perhaps even more obviously, to instrumentally valuable objects - that is, to useful artifacts. To know what a chair or pencil or a computer or a rocket ship is, is to know what it supposed to do. And for these kinds of things, a good one is one that does what it is supposed to do. And to understand - not merely know, but understand - what such an object is, involves knowing, at least in outline, what particular normative standards to hold it to. So just as we understand opera or friendship or the state by understanding what a good opera or a good friendship or a good state is, so we understand pencils and cars and computers by understanding what a good pencil or a good car or a good computer is, and what particular normative standards they must meet. Those who understand pencils know that they ought to have sharp points, just as those who understand classical architecture know that it ought to be spare and minimalistic, or whatever it might be.

Plato and Aristotle thought this was true of any kind of object whatever. That, as I mentioned a moment ago, is what the idea of a Platonic Form involves - that you understand any object whatever by understanding it as an attempt to meet a certain ideal form. But the view finds its clearest expression in Aristotle's Metaphysics. According to Aristotle, what makes an object the kind of object that it is - what gives it its identity - is what it does, or in Greek, its ergon: that is, its purpose, function, or characteristic activity. This is clearest in the case of artifacts. As Aristotle thinks of it, an artifact has both a form and a matter. The matter is the material, the stuff or the parts, from which the object is 
made. The form of the artifact is its functional arrangement or teleological construction. That is, the form is the arrangement of the matter or of the parts which enables the object to serve its function, to do whatever it does. Say for instance that the function of a house is to serve as a habitable shelter, and that its parts are walls, roof, chimney, insulation, and so on. Then the form of the house is that arrangement of those parts that enables it to serve as a habitable shelter - or rather, to be more precise - it is the way the arrangement of those parts enables it to serve as a habitable shelter. ${ }^{10}$

On this view, to be an object, and to have this kind of normative form - that is, to be teleologically constructed - are one and the same thing. Teleological construction is what unifies what would otherwise be, in Aristotle's wonderful phrase, a mere beap into a particular object of a particular kind. Teleological construction or form is also the object of understanding: to understand a thing is to know its form. An architect is not merely someone who knows that the function of a house is to serve as a human habitation. We all know that. He is someone who understands the way building materials may be combined and put together to produce an object suitable for human habitation. So he is someone who knows the form of a house. At the same time, it is the teleological construction or form of an object that supports normative judgments about it. A house with cracks in the walls is less good at keeping the weather out, therefore less suitable for human habitation, and therefore a less good house. The ancient metaphysical thesis of the identification of the real with the good follows readily, for this kind of badness eventually shades off into literal disintegration. ${ }^{11}$ A house with enough cracks in the walls will crumble, and cease to be a house altogether: it will disintegrate back into a mere heap of boards and plaster and bricks.

Aristotle extended this account of artifactual identity to living things with the aid of the view that a living thing is a thing with a special kind of form. A living thing is a thing so designed as to maintain and reproduce itself, that is, to maintain and reproduce its own form. It has what we might call a self-maintaining form. So it is its own end; its ergon or function is

\footnotetext{
${ }^{10}$ Understanding the object is understanding the way the arrangement of the parts enable it to serve its function because you could of course just see how the parts are spacially situated with respect to each other without insight as to how they work together. Then you would not know, for instance, how to make a good substitution for a missing or broken part.
} 
essentially to be - and to continue being - what it is. And its organs, instincts, and natural activities are all arranged to that end. The function of a porcupine, for instance, is to be a porcupine, and to continue being one, and to produce other porcupines. Someone who really understands porcupines knows how it does that - that is, knows how the parts of a porcupine work together to keep the porcupine and its species going. Such a person, then, knows the form of a porcupine. And knowing the form of a porcupine, he is able to make the specific kind of normative judgment that applies to porcupines. He can tell when the porcupine he is considering is bealthy or unbealthy, for instance.

Now let me try to make the relevance of this clear. I remind you again of the Razzian thesis from which I started. Raz says:

The very idea of opera, friendship, or the state is a normative idea in that we understand the concept of an opera or friendship or of the state in part by understanding what a good opera is like, or a good, or successful friendship, or a good state.

Suppose something like Plato and Aristotle's theory of objects is true. Then it is not merely socially dependent objects like opera, friendship, and the state, ${ }^{12}$ but any objects whatever that are, in the operative sense, normatively understood. We understand any kind of thing by understanding what a good or well-functioning thing of its kind is, and so by understanding the norms associated with it. Then we will say that Raz arrived at the idea that values and norms are socially dependent only because he happened to focus his attention on examples of socially dependent objects. He would otherwise have seen that value bears no special relation to socially-dependent objects, for the world insofar as we can understand it is necessarily shot through with values. The fact that the norms associated with a living organic being support the normative judgments bealthy and unhealthy is important here. Judgments of health are the most naturalistic of our normative judgments. No one would claim that health is a socially dependent value.

11 As Raz himself notices in footnote 18, there is vague boundary between being a very bad member of a kind and not being a member at all.

12 Assuming for now, with Raz, that these are socially dependent objects, although I do not actually think that is true of friendship and the state. 
As Aristotle saw it, a living organism appears to be in the business of being what it is. That seems to be its function. Kant thought that something like this is also true of beautiful objects. They do not reproduce themselves, or act so as to keep themselves in existence, to be sure, the way a living organism does. But like living organisms, they have an overwhelming appearance of working hard at meeting normative standards that are given not by something outside of themselves, but simply by their own nature. They are, as Kant says, purposive without purpose. Perhaps this is why for Kant, biological teleology and aesthetics are two branches of the same subject: they treat of two kinds of things that seem to try to meet standards given by their own nature. I note that Raz should agree with this view of aesthetic objects, since he also thinks that the function of opera, for instance, is to meet the normative standards inherent in opera. That is to say, the function of opera is to be good opera. And since opera is defined in terms of good opera, that in turn implies that the function of opera is to be opera. In this respect, an opera is like a living thing - like a porcupine, say. It is in the business of trying to be a good instance of its kind.

Perhaps, though, we will want to add that the very best aesthetic objects go beyond even this, and seem to meet standards entirely unique to their particular selves. ${ }^{13}$ There is a terrible self-sufficiency about the most beautiful things, as if all they need is to be what they individually are. Kant, I believe, thought we encountered such things more often in nature than in art. You have got to learn to enjoy opera, and to that extent, you have to see it as the instance of a type. But take sunsets. Raz claims that the beauty of sunsets is not socially dependent, but that access to that beauty is. He thinks that appreciating sunsets is a social practice. But I think you could be dazzled by a spectacular sunset even if it is the only one you ever saw, and no one in your culture talked about such things. It might just strike you as being perfect of its kind, where its kind is given just by itself. That is what the most beautiful things are like.

Moving from the sublime to the ridiculous, I return to the healthy porcupine. I have just claimed that the criteria of a healthy porcupine are build into the very idea of a porcupine in much the same way that the criteria of an excellent opera are built into the very idea of an opera. This may make you feel that we have got derailed somewhere. Earlier I mentioned Raz's view that there is two-stage process embedded in evaluation: we judge a

13 This is also true of the very best people, but that is a story for another day. 
thing to be good because it is good of its kind. "We might say 'The lecture was good because it was a good lecture."' (REF) Maybe you do not feel very tempted to say that the porcupine is good because it is a good porcupine, or because it is a healthy porcupine. But, as I pointed out before, neither are we tempted to say that an assassin is good because she is a good assassin. The truth is that the values that are in this way internal to objects are not the end of the story. Although this is not quite Nietzsche's question, we can ask it in his words: what is the value of these values?

Someone might be tempted to say that the values realized by good assassins and healthy porcupines will not matter to you unless you care about assassins and porcupines. The question is whether you go in for such things, whether you happen to care about them. But there is no need to get subjectivistic here. The question is actually whether you have reason to care about the object in question. Or better, whether you have to care about it. My point is that the reason to care about an object is not given merely by the fact that the object realizes the values in terms of which it is defined.

You do have reason to care about the values internal to a thing, or perhaps even have to care about those values, when the thing is in a certain way yours. You have reason to care about your own health, for instance, because a certain physical life is yours, and your health is the excellence of that physical life. When I say that you "have to" care about it, I mean this: You do not have to go in for health, the way someone might go in for architecture or football, in order to care about it, or to have reason to. A minimal level of concern is all but guaranteed by the fact that the body in question, the physical life in question, is yours. ${ }^{14} \mathrm{I}$ myself believe, although this is not the place to argue the case in detail, that there are normative standards internal to action, and that the necessity of caring about those is given by the simple fact that you have to act. The hypothetical imperative, or principle of instrumental reason, provides one example. You do not have to go in for instrumental reason. A minimal level of concern for your own efficacy is all but guaranteed by the fact that you have to act. Perhaps you do not thoughtfully and carefully choose the most effective

14 I am not saying that the fact that the physical life is yours grounds a minimal concern for it that then provides you with a reason to pursue it. I am trying to explain how the fact that the life is yours constitutes a reason to care about it, and explaining how the fact motivates you is part of explaining how it constitutes a reason. 
means to your end, but you are not trying to realize an end at all unless you choose $a$ means. A more controversial example, which I would also defend, is Kant's categorical imperative, the principle of autonomy. You do not have to go in for autonomy. A minimal level of concern for your own autonomy is all but guaranteed by the fact that your actions are, and must be, yours. The choice of your own law or principle is implicit in the very act of deciding what to do.

What does Raz have to say about health? I said a few minutes ago that no one would claim that health is a socially dependent value. Raz, of course, does not claim that all values are socially dependent. Instrumental values are not socially dependent. In his first lecture Raz says that health is an instrumental value; what it gets you is survival. In a footnote he adds that of course health might be valuable in other ways too. What I have already said suggests that health is not an instrumental value. Health is not a value because it gets you something - survival - but because you have already got something of which it is the internal excellence - namely a physical life. ${ }^{15}$ Of course I am not denying that there are people who try to be healthy for the sake of survival - or rather longevity. ${ }^{16}$ People do want to be healthy in order to survive longer. But people also want to survive longer only if they will be sufficiently healthy. Raz, as we will see in a moment, thinks that second kind of preference shows that life must contain values in order to be valuable, while on my view, it is very nearly grounded in a tautology. If health is the goodness of physical life, then the preference for living only when you are sufficiently healthy is a preference for living only when life (or at least physical life) is sufficiently good. Health is not some independently

15 In the same way, the value we set on efficacy in general is not an instrumental value. We do not adopt the hypothetical imperative, the general principle of taking the means to our ends, because adopting that principle serves some end. We could not do that, because that would be an exercise of the principle itself, and so we would already have had to adopt it. Rather, the reason we value efficacy in general is because we already have something - namely a life constituted by action - of which it efficacy is one of the excellences. Confusion about this point is the source of much confusion in the theory of practical reason. Even Kant himself, at least in the Groundwork, does not get it quite right. See my papers "The Normativity of Instrumental Reason" and "Human Action and the Kantian Imperatives."

${ }^{16}$ Just as there are people who try especially hard to be efficacious when the end is one that matters a lot, to follow up on the comparisons in my last footnote. 
good thing that continued survival might or might not enable you to obtain or keep, something for which life provides you with an opportunity. I am not sure whether Raz would disagree with this or not, but he does say some things about values other than health that seem to me to be out of harmony with it, as I will explain.

Earlier I mentioned that Raz does not claim that all values are socially dependent. His theory allows for a distinction between (i) values that depend on social practices, such as those of opera; (ii) values that do not depend on social practices but to which we have access only through social practices, such the beauty of sunsets; and (iii) values that are not socially dependent at all, such as instrumental values and some moral values. But Raz does want to make an important claim about social dependence. Raz first puts forward what he calls "the special social dependence thesis," which claims that some values depend on the existence of social practices. Then he adds what he calls a "general social dependence thesis," which claims that "with some exceptions, all values depend on social practices either by being subject to the special thesis or through their dependence on values which are subject to the special thesis"(REF).

When I first hit that phrase "with, some exceptions, all..." I though it was just a curiously incautious way of saying "most." But it turns out there is more to it than that. Although he thinks that not all values are directly or indirectly socially dependent, Raz does think that the important values are, because "the values which can give a meaning and a purpose to life are socially dependent." (REF) Raz concludes that "the whole point of being a valuer is that one can appreciate and respect values, and to the extent that they are socially dependent there is no point to being a valuer, unless there are sustaining practices making possible the existence of values"(REF)

The idea that cultural values are what give life value strikes me as being wrong in the same way that the idea that health could give life value would be wrong. Or rather, it is wrong unless we understand it to be a kind of tautology, like the one that is involved in the thought that you prefer to survive only if your health is sufficiently good. Just as I think we necessarily value health because we have a physical life, so I think we necessarily value cultural values because it is our nature, as human, to have a cultural life. It is not as if cultural values were something out there that human life (luckily) puts us in the way of, and that then make human life valuable. Nor does Raz think so; in a way that is what creates the problem. Two of Raz's professed theses - that there is no point to values without valuers, 
and that there is no point to being valuers without value, seem to leave his theory chasing its own tail. We could not coherently care about life only because it provides us with an opportunity to realize cultural values, any more than we could coherently care about survival only because it provides us with an opportunity to be healthy. We have to care about health because we have a physical life. And we have to care about culture because the specific form of human life, of our life, is cultural. Here I get some help from Kant.

Kant argues that the fundamental characteristic of humanity is the power to set our own ends. In an essay called "Conjectures on the Beginnings of Human History" he makes it clear that he does not just mean that reason, in the guise of morality, gives a thumbs up or a thumbs down to the ends proposed by sensibility. Rather, reason, working through a power Kant calls "comparison," actually proposes new kinds of ends. I have argued, and think it is Kant's view, that self-consciousness is the source of reason. Once you can reflect on the fact that you are inclined to do something, you can ask yourself whether to do what you are inclined to do or not, and then you need a reason. Self-consciousness, and question it brings with it, creates a problem. Reasons, and ultimately values, are the solution. But this same self-consciousness also creates an opportunity. Kant charmingly makes the point through the story of the Garden of Eden, which he turns into a story about the origin of reason. Human beings instinctively eat certain kinds of fruit - make it pears - but we were not instinctively drawn to those fateful apples. Rather, Eve noticed that the apples were like the fruit she instinctively ate, and perhaps also that some creatures who did eat the apples were like her. Reflecting on these comparisons, Eve had the first new idea in history: "You know those apples," she says to herself, "I could eat one of those." Kant says when this happened, man "discovered in himself an ability to choose his own way of life without being tied to any single one like the other animals." ${ }^{\prime 18}$

In other words, when we became free and rational, we also became cultural. We can, and necessarily do, devise different ways of life, and choose among them. Notice there are

17 In Kants gesammelte Shriften, the standard Prussian Academy edition of Kant's works (Berlin), Volume VIII. In English translation by H. B. Nisbet in Kant: Political Writings, 2nd edition, edited by Hans Reiss. (Cambridge: Cambridge University Press, 1991), pp. 221-234.

${ }_{18}$ In the Prussian Academy Edition of Kants gesammelte Shriften, p. 112; in Kant: Political Writings, cited above, p. 224 
two aspects to culture so understood. First, we devise different ways of carrying out the activities we share with the other animals - eating, finding mates, raising families, and so on. All animals perform those activities, but the other animals perform them in biologically determined ways; while we generate a whole range of different possible ways, which characterize different cultures. Second, we develop totally new kinds of activities, activities in which the other animals do not engage in at all - the activities associated with the fine arts, scholarship, science, religion, and generally Raz's "socially dependent values." The need for reasons and values arises from the problem posed by self-consciousness, and culture arises from its solution. Cultural life just is the human form of life.

So I do not think it is quite right to suggest that socially dependent values give value to life. I think that it is right instead to say this: Given that human beings must lead a cultural life, we must care about the excellences of a cultural life, in much the same way that given that we must lead a physical life, we must care about health, the excellence of a physical life. I do not mean for that "must" to convey the idea that cultural values are not sources of joy. I mean instead to be proposing an explanation why these values are, for us, necessarily sources of joy, just as physical excellences are. But cultural values do not give value to life, as if from outside. They are simply the excellences of human life itself.

It is possible that I have misunderstood Raz here, and am therefore being unfair. I am taking Raz to be making the same point when he says that the point of being a valuer is realized only when one is exposed to values and when he says that values give life meaning. If so there is another problem here, resting in the fact that the first formulation refers to both good and bad values and the second mainly to good ones. That is, on one way of understanding the idea that the point of being a valuer is realized in valuing, good and bad values are equally involved. It is a shame to be human and fail to love beautiful things, but it is also a shame to be human and fail to be offended by ugliness and vulgarity, or say to hate injustice. A life lived without friendship is hardly recognizably human; but so is a life lived without outrage, contempt, resentment, and grief. One's capacity for valuing is equally expressed and realized in responding to the good, the bad, and the deprivation of the good. But it seems that a human life could not be graced by disdain for the ugly in the way perhaps it can by a love of the beautiful.

To be clear, Raz is not guilty of holding that socially-dependent values give value to valuers, or people, in this sense: he does not think that you have to realize cultural values in 
your life in order to be worthy of moral respect and consideration. He only wants to claim that you need values to realize the point of being a valuer. One might say in the same spirit that you need healthy physical activity to realize the point of having a physical life, and that seems right. But Raz does not seem to notice the importance of the resulting asymmetry. I will have to ask my reader to hang on tight here, for the Nietzschean language is about to get completely out of hand. The asymmetry is that valuers are valuable whether or not their point is realized, while values are valuable only if their point is realized. When I say that Raz does not see the importance of that, I mean that Raz seems to think that this issue about the moral value of valuers is just a separate point, orthogonal to his view. But it is not; there is a reason for it. The value of values comes from valuers, and not the reverse, and that fact that we are the source of value - is also what makes us worthy of moral consideration. Humanity, not the standards implicit in social practices, is the ultimate source of value. ${ }^{19}$

${ }_{19}$ Despite the way it sounds I do not mean to deny that the other animals are sources of value, although I think that their status as such depends on us - we must see them as sources of value. For a discussion of these matters see The Sources of Normativity (Cambridge 1996), Lecture 4, sections 4.3.6-4.3.10. 